\title{
LADY GAGA: UNINDO MODA, MÚSICA POP E ARTE
}

\section{Renata Pasquini Cursino' \\ Letícia Guedes de Paula² \\ Paulo Roxo Barja ${ }^{3}$}

Resumo: O trabalho em questão insere-se no contexto de uma pesquisa mais ampla a respeito da relação entre Moda e Arte. Analisam-se aspectos da obra da artista pop Lady Gaga, que desenvolve seus trabalhos multifacetados sob uma perspectiva segundo a qual Moda e Música são dimensões da Arte Pop. A proposta de Lady Gaga é influenciada por Andy Warhol e transparece não apenas em suas produções artísticas, como também em suas declarações à imprensa, objeto de análise deste estudo. Gaga busca o status de Arte para seus trabalhos, independentemente do aspecto comercial que estes possam apresentar. Sua proposta, que pode ser resumida na afirmação "o que é feito com Arte permanece", pode ser aplicada indistintamente a qualquer dos aspectos de sua obra, Música e Moda incluídas.

Palavras-chave: Arte; Moda; Pop; Pop Art.

\footnotetext{
1 Universidade do Vale do Paraíba, Brasil. E-mail: re_pasquini@yahoo.com.br.

2 Universidade do Vale do Paraíba, Brasil. E-mail: leticiaguedes_07@hotmail.com.

3 Universidade do Vale do Paraíba, Brasil. E-mail: barja@univap.br.
} 